Re-Print: Association of Early Favipiravir Use with Reduced COVID-19 Fatality among Hospitalized Patients

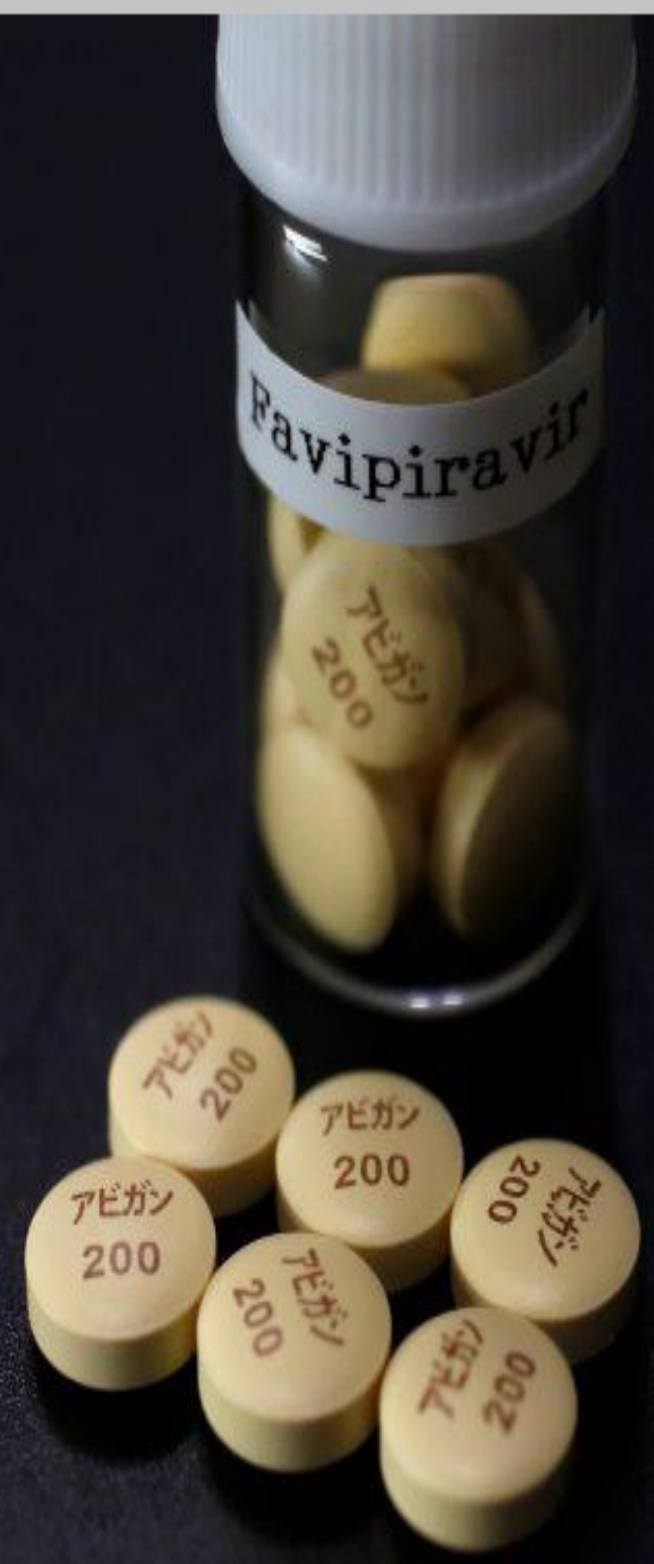

\title{
AUCTORES
}

Globalize your Research

\section{Cancer Research and Cellular Therapeutics}




\author{
Authored by \\ Ercan Karatas $^{1 *}$, Lacin Aksoy ${ }^{2}$, Ersin Ozaslan ${ }^{3}$ \\ ${ }^{1}$ Department of Internal Medicine, Tuzla State Hospital, Istanbul, Turkey \\ ${ }^{2}$ Department of Family Practices, Marmara University Medical Faculty, \\ Istanbul, Turkey \\ ${ }^{3}$ Acibadem Hospitals Group, Medical Oncology, Kayseri, Turkey.
}

\title{
Published Date
}

August 23, 2021

\author{
Published in the Journal of \\ Cancer Research and Cellular Therapeutics \\ Auctores Publishing, LLC \\ 16192 Coastal Highway \\ Lewes, DE 19958, \\ United States of America.
}




\title{
Re-Print: Association of Early Favipiravir Use with Reduced COVID- 19 Fatality among Hospitalized Patients
}

Ercan Karatas*1, Lacin Aksoy ${ }^{2}$, Ersin Ozaslan ${ }^{3}$

${ }^{1}$ Department of Internal Medicine, Tuzla State Hospital, Istanbul, Turkey

${ }^{2}$ Department of Family Practices, Marmara University Medical Faculty, Istanbul, Turkey

${ }^{3}$ Acibadem Hospitals Group, Medical Oncology, Kayseri, Turkey

*Corresponding Author: Ercan Karatas, Department of İnternal Medicine, Tuzla State Hospital, Istanbul 34959, Turkey.

Received Date: August 04, 2021; Accepted Date: August 13, 2021; Published Date: August 23, 2021

Citation: E Karatas, L Aksoy, E Ozaslan. (2021) Association of Early Favipiravir Use with Reduced COVID-19 Fatality among Hospitalized Patients. J.Cancer Research and Cellular Therapeutics. 5(4); Doi: 10.31579/2640-1053/093.

Copyright: @ 2021 Ercan Karatas, This is an open-access article distributed under the terms of the Creative Commons Attribution License, which permits unrestricted use, distribution, and reproduction in any medium, provided the original author and source are credited.

\begin{abstract}
Background: The antiviral agent favipiravir is an RNA-dependent RNA polymerase (RdRp) inhibitor.

Materials and Methods: We examined patients with a clinical, laboratory, and radiological diagnosis of severe coronavirus disease 2019 (COVID-19) pneumonia. We investigated the effect of administering enteral favipiravir at a $2 \times 1,600 \mathrm{mg}$ loading dose and $2 \times 600 \mathrm{mg}$ maintenance dose for 5 days in addition to the standard COVID-19 treatment.

Results: In total, 180 patients, who were hospitalized at the Istanbul Tuzla State Hospital and received favipiravir treatment between March 20, 2020 and May 30, 2020, were examined. Of these, 47 patients died. Thirty-three of the patients who died were aged over 65 years $(70 \%)$, indicating that fatality was higher in elderly patients. Most of those who died had at least one comorbidity. Of the 101 patients who initiated favipiravir within $\leq 3$ days of hospitalization, 17 died (17\%). Of the 79 patients who initiated favipiravir after $>3$ days of hospitalization, 30 died $(38 \%)(\mathrm{P}=0.002)$.
\end{abstract}

Conclusion: We found that initiation of favipiravir within the first $72 \mathrm{~h}$ after the onset of disease symptoms reduced fatality in patients with COVID-19.

Keywords: COVID-19; favipiravir; time-to-treatment; hospitalization

\section{Introduction}

The novel severe acute respiratory syndrome coronavirus 2 (SARS-CoV2) has spread globally and caused an unprecedented pandemic, with 150 million cases and over 3 million deaths in a year. SARS-CoV-2 is an enveloped, positive-sense, single-stranded RNA virus responsible for causing coronavirus disease 2019 (COVID-19) [1]. Although various strategies have been developed to treat COVID-19, there is still no standard treatment [2]. Antivirals that have been used to treat other viral infections are also being tried against COVID-19 [3].

Favipiravir is an oral broad-spectrum anti-viral agent that selectively and potently inhibits the RNA-dependent RNA polymerase (RdRp) of RNA viruses [4]. Favipiravir has shown potent in vitro activity against SARSCoV-2 [5]. Consequently, favipiravir has been added to the options available for treating COVID-19 [6]. It was determined that favipiravir treatment reduced viral clearance and provided clinical and radiological improvement [7]. In Turkey, Ministry of Health suggested the usage of favipiravir as an antiviral according to clinical researches in Europe.

In our study, we investigated whether the time when favipiravir is initiated influences the risk of fatality in hospitalized patients with severe COVID19 pneumonia.

\section{Material and Methods}

\section{Patients}

This study was carried out at Tuzla State Hospital, Istanbul, Turkey, with approval of the Marmara University Faculty of Medicine Ethics Committee after obtaining permission from the Scientific Research Unit of the Ministry of Health and the Istanbul Provincial Health Directorate (Marmara University Faculty of Medicine Research Ethics Committee; 
approval no.: E.70737436-050.01.04-2000202899; date: September 29, 2020). Patients with severe COVID-19 pneumonia, who were admitted to Tuzla State Hospital between March 20, 2020 and May 30, 2020 and treated with favipiravir at any stage of their treatment, were examined retrospectively. All patients with their or their family consent used favipiravir. The study conducted according to their health records with no personal information. Therefore, informed consent not asked to the patients whether their families. The study included patients aged over 18 years who were not pregnant, had severe pneumonia (respiratory rate $>30 / \mathrm{min}$ ) with or without comorbidities and/or severe respiratory distress (dyspnea or use of extra respiratory muscles) and/or fingertip oxygen saturation $<90 \%\left(\mathrm{PaO}_{2} / \mathrm{FiO}_{2}<300\right.$ in patients receiving oxygen), were treated with favipiravir at any stage of their treatment, and had bilateral multi-lobar ground glass opacities observed in a computed tomography (CT) scan of the lungs. During the first half of the study period, according to the COVID-19 treatment protocol followed in our country, favipiravir could be administered to patients in whom standard COVID-19 treatment was not successful. Therefore, favipiravir was started later in some of our patients. However, the treatment protocol changed in the second half of our study, and favipiravir was used from the beginning of the treatment.

\section{Statistical Analysis}

The research data were collected retrospectively through the Tuzla State Hospital registration system. Descriptive statistics were used to analyze categorical variables, represented as numbers, and continuous variables, represented as mean $\pm \mathrm{SD}$ or median and interquartile range. The results were compared using $t$-test with the software SPSS 22.0 Statistics (IBM, Armonk, NY, USA).

\section{Results}

We examined 180 patients who were hospitalized with severe pneumonia in the Istanbul Tuzla State Hospital and treated with favipiravir. The median age of the patients was $59 \pm 17.4$. Of these, 108 patients were aged $\leq 65$ years. Fifteen of these patients died, indicating a fatality rate of $12 \%$ $(15 / 108)$. In addition, 32 of 72 patients who were aged $>65$ years died; the fatality rate of these patients was $45 \%(32 / 72 ; P<0.001)$. This indicates that fatality increased with an increase in age. In total, 47 patients died, of whom 30 were male and 17 were female.

We observed that as the number of comorbidities increased, the fatality rate also increased. In our study, 113 of 180 patients (63\% of all patients) had at least one comorbidity (Fig. 1). The main comorbidities were hypertension ( 79 patients), hyperlipidemia (57 patients), diabetes mellitus (52 patients), and coronary artery disease (33 patients). Of the 47 patients who died, 42 had at least one comorbid disease (89\%). Cough (94 patients, $52 \%$ ), dyspnea ( 86 patients, $47 \%$ ), and fever (82 patients, $45 \%$ ) were the topmost initial clinical findings (Fig.2).

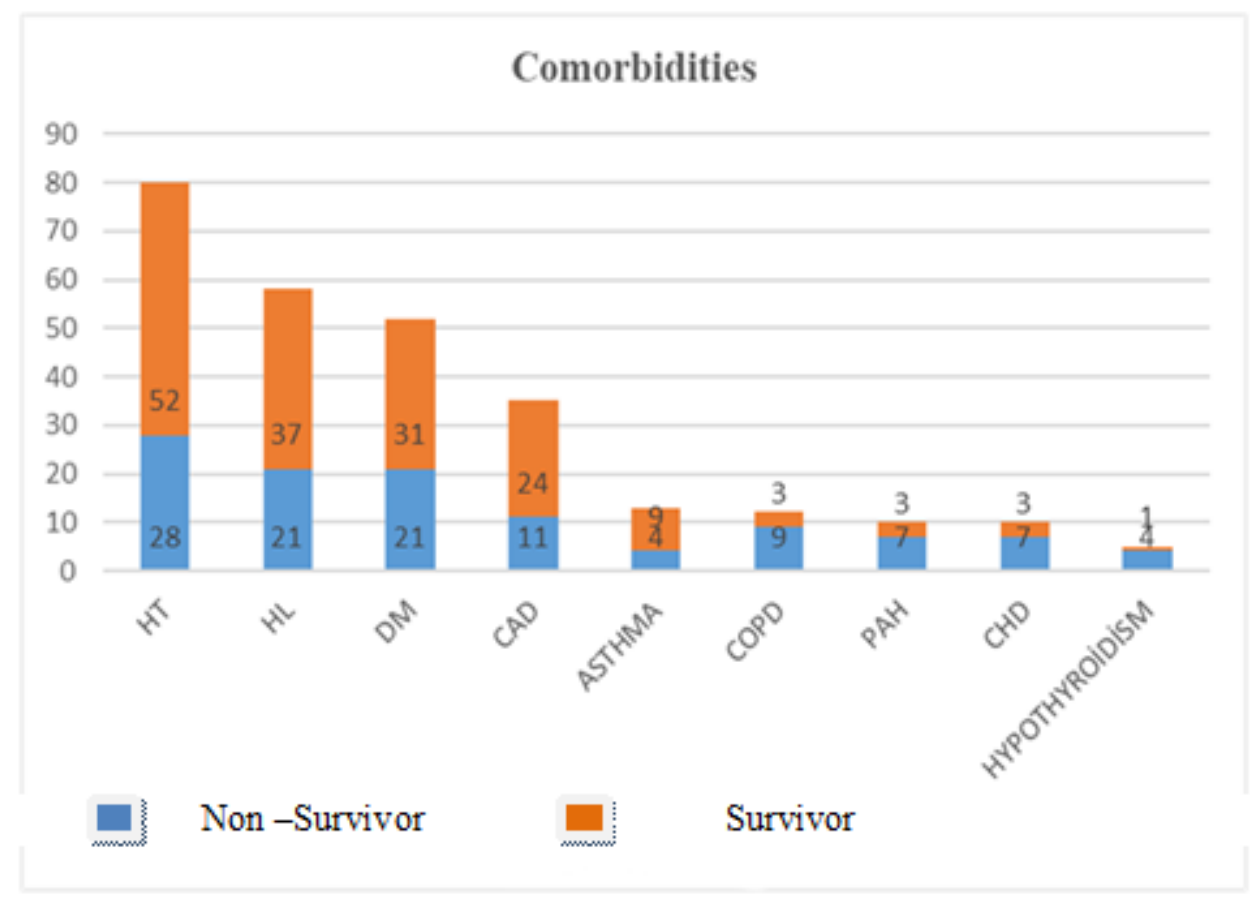

Figure 1: Relationship between comorbidities and survival(X: Number of patients, Y: Types of comorbities) Survivors, non-survivors

HT, hypertension; CAD, coronary artery disease; PAH, peripheral artery disease; HL, hyperlipidemia; CHF, congestive heart failure; DM, diabetes mellitus; COPD, chronic obstructive pulmonary disease. 


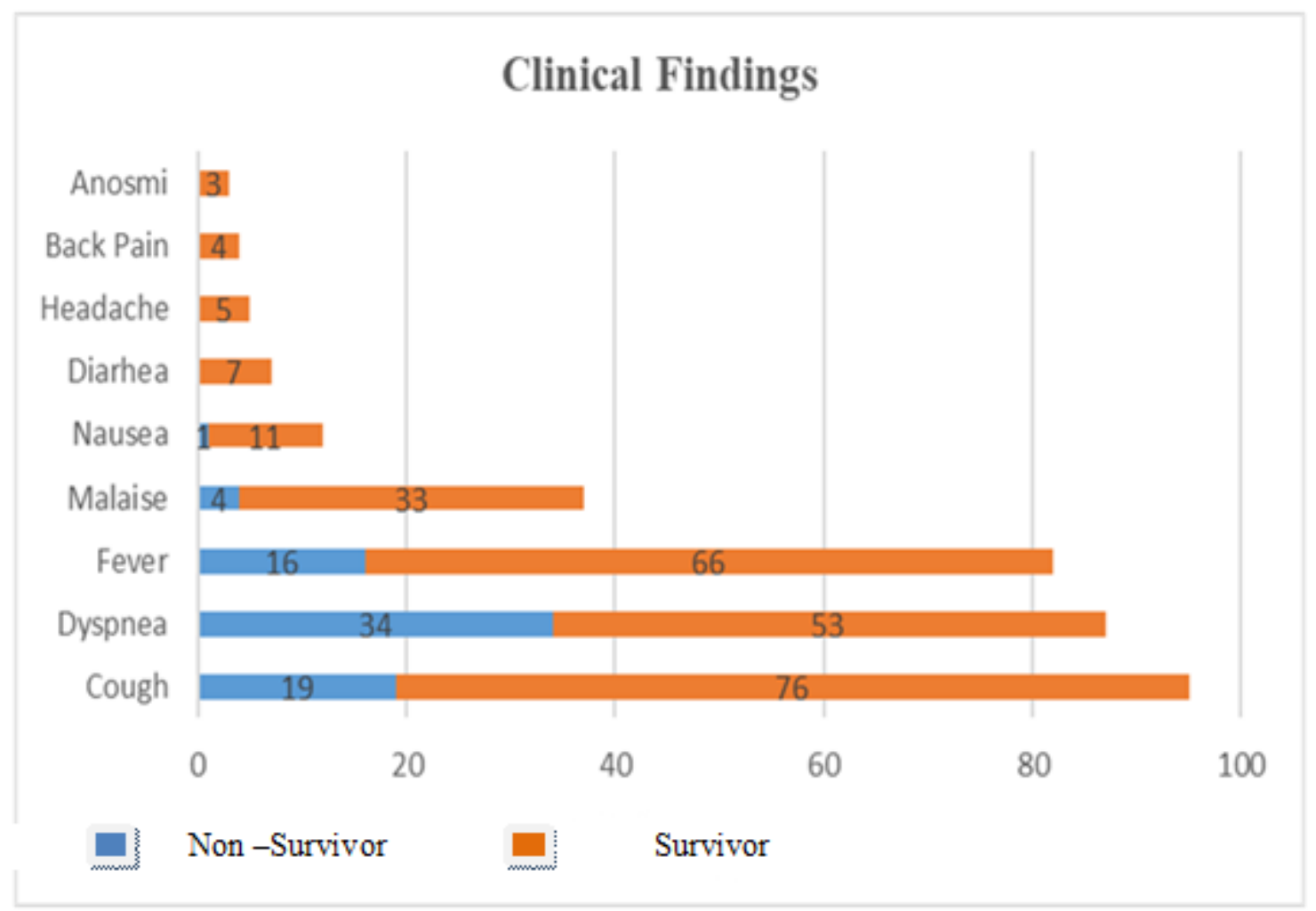

Figure 2. Clinical findings (X: Symptoms, Y: Number of patients)

Among the hematological parameters, lymphopenia (lymphocyte count $<1 \times 109 / \mathrm{L}$ ), low hemoglobin levels (hemoglobin $<12 \mathrm{~g} / \mathrm{dL}$ ), leukocytosis (leukocyte count $>7.5 \times 109 / \mathrm{L})(\mathrm{P}=0.001)$ and neutrophilia (neutrophil count $>7.5 \times 109 / \mathrm{L})(\mathrm{P}=0.003)$ are associated with disease severity. In this study, disease severity and platelet count were not correlated $(\mathrm{P}>0.5)$. C-reactive protein (CRP) levels were increased in the patients; survivors had mean CRP values of about $85 \mathrm{mg} / \mathrm{L}$, while non-survivors had mean values of $122 \mathrm{mg} / \mathrm{L}$, which correlates with disease severity and prognosis $(\mathrm{P}=0.004)$. Other predictors studied were the serum ferritin and lactate dehydrogenase (LDH) levels. High levels of ferritin $(>200 \mu \mathrm{g} / \mathrm{L})$ and LDH $(>260$ units/L) are associated with disease severity $(\mathrm{P}=0.001)$. Survivors showed significantly higher plasma D-dimer levels than the non-survivors. Among the coagulation parameters studied, D-dimer level $>1,000 \mathrm{ng} / \mathrm{mL}$ was a predictor of fatality $(\mathrm{P}=0.0003)$. Clinicians should consider low lymphocyte, leukocyte, and hemoglobin counts as well as the CRP, LDH, ferritin, and D-dimer serum levels. These serum values can be used in risk stratification to predict severe and fatal COVID-19 in hospitalized patients (Table 1).

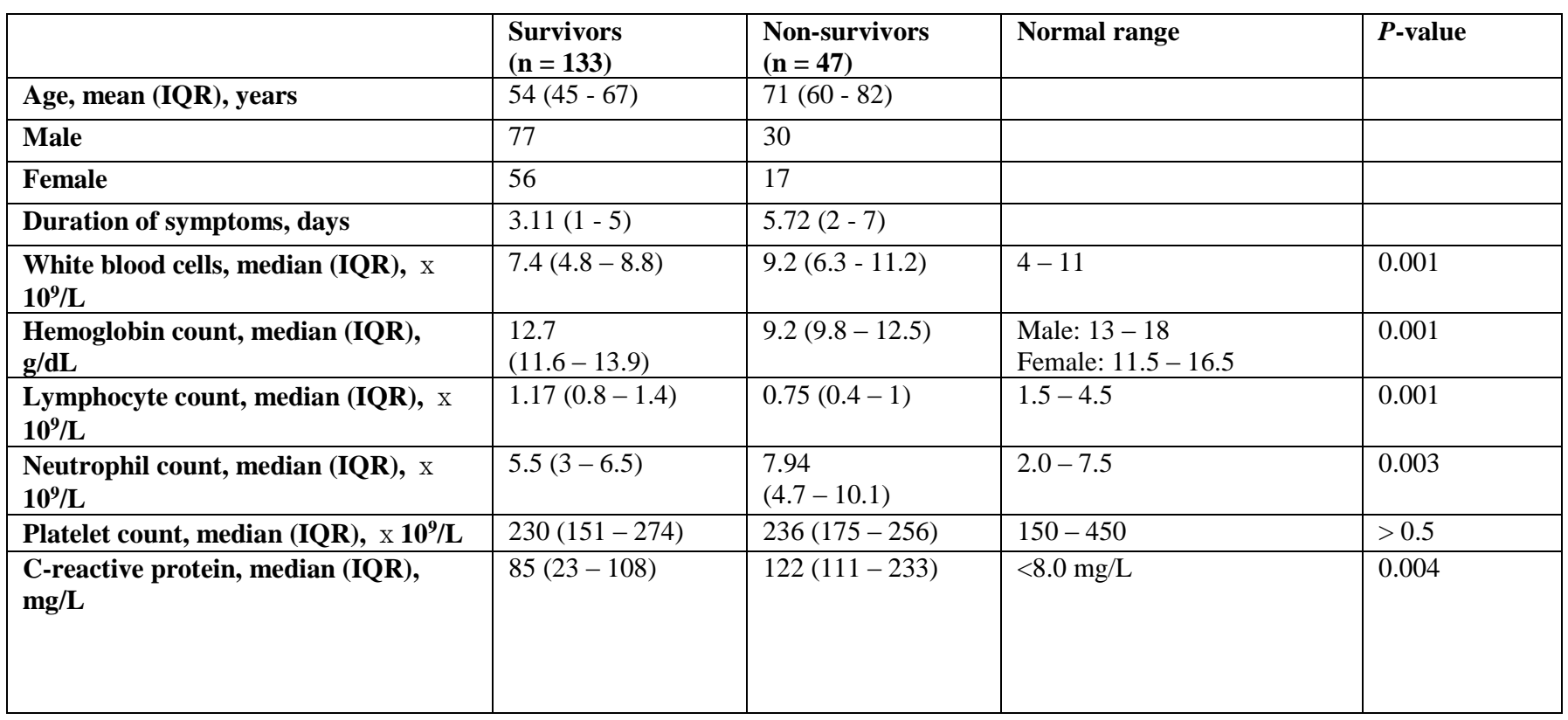




\begin{tabular}{|l|l|l|l|l|}
\hline Ferritin, median (IQR), $\boldsymbol{\mu g} / \mathbf{L}$ & $330(94-339)$ & $\begin{array}{l}812 \\
(218-1,043)\end{array}$ & $\begin{array}{l}\text { Females: } 10-200 \mu \mathrm{g} / \mathrm{L} ; \\
\text { males: } 30-300 \mu \mathrm{g} / \mathrm{L}\end{array}$ & \begin{tabular}{l}
0.001 \\
\hline
\end{tabular} \\
\hline $\begin{array}{l}\text { Lactate dehydrogenase, median (IQR), } \\
\text { units/L }\end{array}$ & $333(222-369)$ & $528(368-640)$ & $110-210$ & 0.001 \\
\hline Creatinine, $\mathbf{m g} / \mathbf{d L}$ & $\begin{array}{l}0.9 \\
(0.7-1.025)\end{array}$ & $1.3(0.7-1.7)$ & $<1.2$ & 0.004 \\
\hline ALT(Alaninetransaminase), U/L & $31(22-39)$ & $33(17-35)$ & $<24$ & $>0.5$ \\
\hline Na, mEq/L & $135(133-139)$ & $136(133-140)$ & $135-145$ & $>0.5$ \\
\hline D-Dimer, median (IQR), ng/mL & $\begin{array}{l}830 \\
(430-1,210)\end{array}$ & $\begin{array}{l}2,897 \\
(1,070-3,185)\end{array}$ & $<500$ & 0.0003 \\
\hline
\end{tabular}

$P$-values were calculated using Pearson's chi-square test.

Abbreviation: IQR, ALT

Moreover, the need for advanced respiratory support increased in patients who initiated favipiravir after $>72 \mathrm{~h}$ (Table 2 ). When we evaluated the timeto-treatment after hospitalization, we found that the fatality rate was lower in those who received favipiravir treatment within the first $72 \mathrm{~h}$ of hospitalization ( $\mathrm{P}=0.002$; Fig. 3).

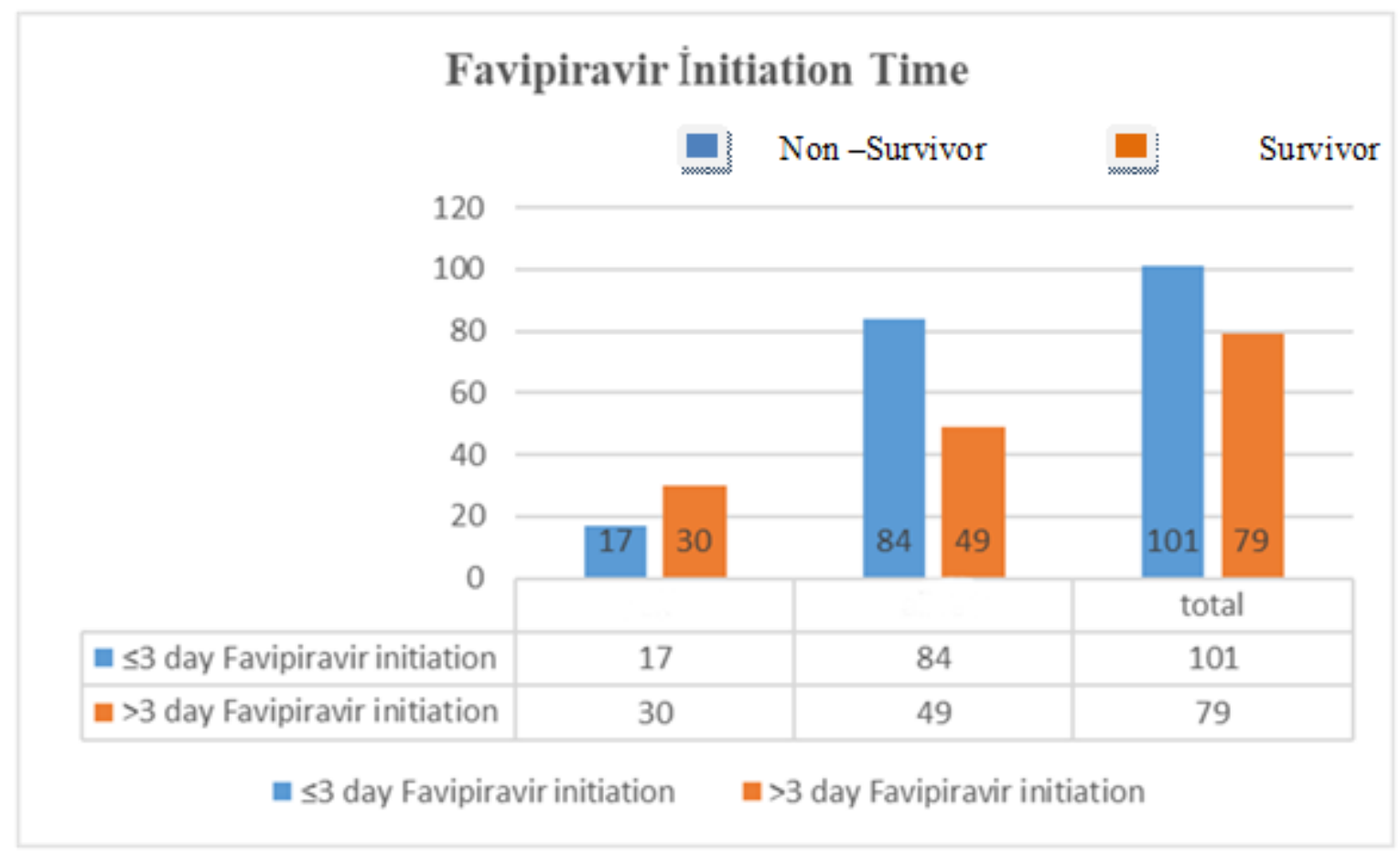

Figure 3. Relationship between the time of initiating favipiravir and survival (X: Number of patients, Y: Number of survivors and non-survivors)

\begin{tabular}{|l|l|l|l|}
\hline Favipiravir initiation time & $\begin{array}{l}\leq \mathbf{7 2} \mathbf{~ h} \\
(\mathbf{n}=\mathbf{1 3 3})\end{array}$ & $\begin{array}{l}\mathbf{> 7 2} \mathbf{~} \\
(\mathbf{n}=\mathbf{4 7})\end{array}$ & $\boldsymbol{P}$-value \\
\hline Supplemental oxygen & 104 & 2 & 0.0001 \\
\hline High-flow nasal oxygen & 2 & 7 & 0.02 \\
\hline $\begin{array}{l}\text { Non-invasive mechanical } \\
\text { ventilation }\end{array}$ & 4 & 3 & 0.3 \\
\hline \begin{tabular}{l} 
Invasive ventilation \\
\hline
\end{tabular} & 23 & 35 & 0,001 \\
\hline
\end{tabular}

Table 2. Respiratory support 


\section{Discussion}

COVID-19 is a multisystemic inflammatory disease [8]. Currently, there is no universal standard for drug treatment, and various combination therapies are being administered [9]. Our standard treatment involves the administration of antivirals (favipiravir), broad spectrum antibiotics, lowmolecular weight heparin, antithrombotic drugs, corticosteroids, and oxygen therapy [10]. For severe COVID-19 pneumonia, cytokine storm, macrophage activation syndrome, and acute respiratory distress syndrome, convalescent plasma, interleukin-6 inhibitors, and anakinra, an interleukin-1 receptor antagonist, are added to the treatment [11]. Combination therapy is currently customized for each patient.

Based on other viral infections, early antiviral therapy is considered more useful in the treatment of COVID-19. The benefit of early antiviral therapy in the treatment of influenza has been observed previously [12, 13]. SARS, Middle East respiratory syndrome (MERS), and COVID-19 are caused by viruses with similar genetic structures [14]. The benefit of early antiviral treatment has also been reported in SARS and MERS [15]. Several clinical trials on COVID-19 have demonstrated that early antiviral therapy is necessary and beneficial.

For instance, Magleby et al. conducted a retrospective cohort study in 678 hospitalized patients with COVID-19 in New York. They demonstrated that high viral load was independently associated with mortality, and that early antiviral therapy prevents increased viral load in the lower respiratory tract by inactivating the viruses in the upper respiratory tract [16]. Weiss et al. determined that the viral load in the upper respiratory tract peaks early in mild cases of COVID-19 (4 days) compared to that in moderate to severe cases ( 8 days). Similarly, viral load in the lower respiratory tract peaks early in mild cases (6 days) compared to that in moderate to severe cases (11 days). This indicates the importance of early diagnosis and the time to initiate treatment [17].

Goyal et al. reported that if a patient receives antiviral therapy in the early phase of infection, there are high chances that the duration of shedding and intensity of the effector immune response may decrease; however, there may be a limited impact on viral area under the curve, possibly owing to higher levels of early SARS-CoV-2 replication [18]. Early antiviral therapy can effectively reduce virus clearance time and prevent the rapid progression of COVID-19. Therefore, COVID-19 patients should receive combination treatment with antiviral agents at an early stage. By reducing the rate, quantity, or duration of viral replication, the degree of direct viral injury to the respiratory epithelium, vasculature, and organs may be minimized. Additionally, secondary processes that depend on viral stimulation, including the activation of inflammatory cells, cytokines, and coagulation, could potentially be minimized if the viral replication is attenuated [19].

According to Saber-Ayad et al., antiviral drugs administered shortly after the onset of symptoms can shorten the course of clinical illness and reduce its infectivity by lowering viral shedding [20]. In another study conducted in Wuhan, $\mathrm{Yu}$ et al. divided 129 hospitalized patients with mild to moderate COVID-19, who were treated with antiviral drugs, into the early antiviral treatment and late antiviral treatment groups. The group receiving early antiviral treatment recovered in 7 days less than the group receiving late antiviral treatment [21].

$\mathrm{Wu} \mathrm{J}$ et al. found that older adults and patients with underlying diseases are more likely to experience severe COVID-19 progression. It is recommended to start antiviral treatment in time to slow the progression of the disease and improve the prognosis [22]. Early antiviral therapy, along with the combination therapy, increases viral clearance and reduces viral load, resulting in fatal complications including cytokine storm, macrophage activation syndrome, and acute respiratory distress syndrome [23]. According to a previous multivariate analysis, one comorbidity and the time from illness to antiviral treatment are statistically significantly associated with the severity of disease [24]. Similarly, since it is not known precisely which patients will have a more severe course of viral infection, antiviral treatment should be initiated without delay, especially in the elderly patients, patients with multiple chronic diseases, and patients who meet the clinical and laboratory criteria for severe COVID19 at the time of onset [25]. Murohashi et al. demonstrated the importance of the early-stage use of a combination of favipiravir and methylprednisolone in severe cases, to achieve a favorable clinical outcome [26] Doi et al. described the successful treatment of patients with COVID-19 using favipiravir to rapidly and substantially clear SARSCoV-2 from nasal secretions irrespective of whether it was started relatively early or later within the first week of infection [27].

Similar to the above-mentioned studies, we found that early antiviral therapy is beneficial and reduces fatality in patients with COVID-19.

The primary defense mechanism against viral infections is the response formed by the humoral immune system. However, in some infectious diseases, such as COVID-19, the immune system may not be able to neutralize the virus. In these cases, it is necessary to use treatments that will reduce the rate of replication of the virus. Early initiation of antiviral drugs will reduce the rate of viral replication and decrease the time required for the humoral defense mechanism to neutralize the virus.

In conclusion, we found that initiation of the antiviral agent favipiravir, an RdRp inhibitor, within the first $72 \mathrm{~h}$ of the onset of disease symptoms significantly reduced fatality. Nevertheless, the research has limitations, such as the fact that the study was conducted with the participation of a small group of patients.

\section{Funding}

No funding required for this study.

\section{Conflicts of Interest}

There is no conflicts of interest regarding researchers that none of the researchers have ever had any funding from private company, shareholder companies and drug companies.

\section{ORCID}

Ercan Karatas https://orcid.org/0000-0002-3133-4199

Lacin Aksoy https://orcid.org/0000-0002-4105-0595

Ersin Ozaslan

\section{Authors' contributions}

\section{Conceptualization: Ercan Karataş}

Data curation: Ercan Karataş

Formal analysis: Laçin Aksoy

Funding acquisition: -

Investigation:Laçin Aksoy

Methodology: Ersin Özaslan

Project administration: Ercan Karataş

Resources: Ercan Karataş

Software: Laçin Aksoy

Supervision: Ersin Özaslan

Validation: Laçin Aksoy

Visualization: Ercsn Karataş

Writing - original draft:Ercan Karataş

Writing - review \& editing: Laçin Aksoy 


\section{References}

1. Sallenave JM, Guillot L. (2020). Innate Immune Signaling and Proteolytic Pathways in the Resolution or Exacerbation of SARS-CoV-2 in Covid-19: Key Therapeutic Targets. Front Immunol. 11:1229.

2. Helmy YA, Fawzy M, Elaswad A, Sobieh A, Kenney SP, Shehata AA. (2020). The COVID-19 Pandemic: A Comprehensive Review of Taxonomy, Genetics, Epidemiology, Diagnosis, Treatment, and Control. J Clin Med. 9(4):1225.

3. Han W, Quan B, Guo Y et al. (2020). The course of clinical diagnosis and treatment of a case infected with coronavirus disease 2019. J Med Virol. 92: 461-463.

4. Furuta Y, Komeno T, Nakamura T. (2017). Favipiravir (T-705), a broad spectrum inhibitor of viral RNA polymerase. Proc Jpn Acad Ser B Phys Biol Sci. 93(7):449-463.

5. Joshi S, Parkar J, Ansari A, et al. (2021). Role of favipiravir in the treatment of COVID-19. Int J Infect Dis. 102:501-508.

6. Du YX, Chen XP. (2020). Favipiravir: Pharmacokinetics and Concerns about Clinical Trials for 2019-nCoV Infection. Clin Pharmacol Ther. 108(2):242-247.

7. Cai Q, Yang M, Liu D, et al. (2020). Experimental Treatment with Favipiravir for COVID-19: An Open-Label Control Study. Engineering (Beijing). 6(10):1192-1198.

8. Yang L, Liu S, Liu J, et al. (2020). COVID-19: immunopathogenesis and Immunotherapeutics. Signal Transduct Target Ther. 5(1):128.

9. Vijayvargiya P, Esquer Garrigos Z, Castillo Almeida NE, Gurram PR, Stevens RW, Razonable RR. (2020). Treatment Considerations for COVID-19: A Critical Review of the Evidence (or Lack Thereof). Mayo Clin Proc. 95(7):1454-1466.

10. Xu X, Ong YK, Wang Y. (2020). Role of adjunctive treatment strategies in COVID-19 and a review of international and national clinical guidelines. Mil Med Res. 7(1):22.

11. Shakoory B, Carcillo JA, Chatham WW, et al. (2016). Interleukin-1 Receptor Blockade Is Associated With Reduced Mortality in Sepsis Patients with Features of Macrophage Activation Syndrome: Reanalysis of a Prior Phase III Trial. Crit Care Med. 44(2):275-281.

12. Wang Y, Wang Y, Chen Y, \& Qin Q. (2020). Unique epidemiological and clinical features of the emerging 2019 novel coronavirus pneumonia (COVID-19) implicate special control measures. Journal of medical virology. 92(6):568-576.

13. Hsu J, Santesso N, Mustafa R, Brozek J, Chen Y L, Hopkins J $P$ et al. (2012). Antivirals for treatment of influenza: a systematic review and meta-analysis of observational studies. Annals of internal medicine. 156(7):512-524.

14. Uyeki T M, Bernstein H H, Bradley J S, Englund J A, File T M, Fry A M, et al. (2019). Clinical Practice Guidelines by the Infectious Diseases Society of America: 2018 Update on Diagnosis, Treatment, Chemoprophylaxis, and Institutional Outbreak Management of Seasonal Influenzaa. Clinical infectious diseases: an official publication of the Infectious Diseases Society of America. 68(6): 1-47.

15. Chan KS. (2003). Treatment of severe acute respiratory syndrome with lopinavir/ritonavir: a multicentre retrospective matched cohort study. Hong Kong Medical Journal. 9: 399-406.

16. Magleby R, Westblade LF, Trzebucki A, et al. (2020). Impact of SARS-CoV-2 Viral Load on Risk of Intubation and Mortality Among Hospitalized Patients with Coronavirus Disease 2019 [published online ahead of print, 2020 Jun 30]. Clin Infect Dis. ciaa851.

17. Weiss A, Jellings $\varnothing$ M, Sommer MOA. (2020). Spatial and temporal dynamics of SARS-CoV-2 in COVID-19 patients: A systematic review and meta-analysis. EBioMedicine. 58:102916.

18. Goyal A, Lurie Y, Meissner EG, et al. (2017). Modeling HCV cure after an ultra-short duration of therapy with direct acting agents. Antiviral Res. 144:281-285.

19. McCullough PA, Kelly RJ, Ruocco G, et al. (2021). Pathophysiological Basis and Rationale for Early Outpatient Treatment of SARS-CoV-2 (COVID-19) Infection. The American Journal of Medicine. 134(1):16-22.

20. Saber-Ayad M, Saleh MA, Abu-Gharbieh E. (2020). The Rationale for Potential Pharmacotherapy of COVID19. Pharmaceuticals (Basel). 13(5):96.

21. Yu T, Tian C, Chu S, et al. (2020). COVID-19 patients benefit from early antiviral treatment: A comparative, retrospective study [published online ahead of print, 2020 Jun 3]. J Med Virol. 10.1002.

22. Wu Z, McGoogan JM. (2020). Characteristics of and important lessons from the coronavirus disease 2019 (COVID-19) outbreak in China: summary of a report of 72314 cases from the Chinese Center for Disease Control and Prevention. JAMA 323:1239-1242.

23. Kim JS, Lee JY, Yang JW, et al. (2020). Immunopathogenesis and treatment of cytokine storm in COVID-19. Theranostics. 11(1):316-329.

24. Wu J, Li W, Shi X, Chen Z, Jiang B, Liu J, Wang D, Liu C, Meng Y, Cui L, Yu J, Cao H, Li L. (2020). Early antiviral treatment contributes to alleviate the severity and improve the prognosis of patients with novel coronavirus disease (COVID19). J Intern Med. 288(1):128-138.

25. Kalil AC. (2020). Treating COVID-19-Off-Label Drug Use, Compassionate Use, and Randomized Clinical Trials during Pandemics.

26. Murohashi K, Hagiwara E, Kitayama T, et al. (2020). Outcome of early-stage combination treatment with favipiravir and methylprednisolone for severe COVID-19 pneumonia: A report of 11 cases [published online ahead of print, 2020 Aug 28]. Respir Investig. 58(6):430-434.

27. Doi Y, Hibino M, Hase R, et al. (2020). A Prospective, Randomized, Open-Label Trial of Early versus Late Favipiravir Therapy in Hospitalized Patients with COVID-19. Antimicrob Agents Chemother. 64(12) 